\title{
Study protocols of three parallel phase 1 trials combining radical radiotherapy with the PARP inhibitor olaparib
}

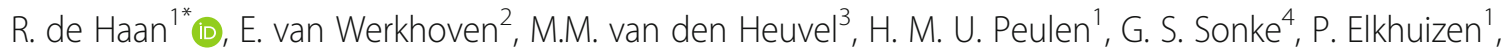
M. W. M. van den Brekel ${ }^{5}$, M. E. T. Tesselaar ${ }^{4}$, C. Vens ${ }^{6}$, J. H. M. Schellens ${ }^{7,8}$, B. van Triest ${ }^{1}$ and M. Verheij ${ }^{1,6}$

\begin{abstract}
Background: Poly (ADP-ribose) Polymerase (PARP) inhibitors are promising novel radiosensitisers. Pre-clinical models have demonstrated potent and tumour-specific radiosensitisation by PARP inhibitors. Olaparib is a PARP inhibitor with a favourable safety profile in comparison to clinically used radiosensitisers including cisplatin when used as single agent. However, data on safety, tolerability and efficacy of olaparib in combination with radiotherapy are limited.

Methods: Olaparib is dose escalated in combination with radical (chemo-)radiotherapy regimens for non-small cell lung cancer (NSCLC), breast cancer and head and neck squamous cell carcinoma (HNSCC) in three parallel single institution phase 1 trials. All trials investigate a combination treatment of olaparib and radiotherapy, the NSCLC trial also investigates a triple combination of olaparib, radiotherapy and concurrent low dose cisplatin. The primary objective is to identify the maximum tolerated dose of olaparib in these combination treatments, defined as the dose closest to but not exceeding a 15\% probability of dose limiting toxicity. Each trial has a separate dose limiting toxicity definition, taking into account incidence, duration and severity of expected toxicities without olaparib. Dose escalation is performed using a time-to-event continual reassessment method (TITE-CRM). TITE-CRM enables the incorporation of late onset toxicity until one year after treatment in the dose limiting toxicity definition while maintaining an acceptable trial duration. Olaparib treatment starts two days before radiotherapy and continues during weekends until two days after radiotherapy. Olaparib will also be given two weeks and one week before radiotherapy in the breast cancer trial and HNSCC trial respectively to allow for translational research. Toxicity is scored using common terminology criteria for adverse events (CTCAE) version 4.03. Blood samples, and tumour biopsies in the breast cancer trial, are collected for pharmacokinetic and pharmacodynamic analyses.
\end{abstract}

Discussion: We designed three parallel phase 1 trials to assess the safety and tolerability of the PARP inhibitor olaparib in combination with radical (chemo-)radiotherapy treatment regimens. PARP inhibitors have the potential to improve outcomes in patients treated with radical (chemo-)radiotherapy, by achieving higher locoregional control rates and/or less treatment associated toxicity.

Trial registration: ClinicalTrials.gov Identifiers: NCT01562210 (registered March 23, 2012), NCT02227082 (retrospectively registered August 27, 2014), NCT02229656 (registered September 1, 2014).

Keywords: Radiotherapy, Radiosensitisation, Olaparib, PARP inhibitor, Phase 1, Dose escalation, TITE-CRM, Dose limiting toxicity

\footnotetext{
* Correspondence: ro.d.haan@nki.nl

'Department of Radiation Oncology, The Netherlands Cancer Institute,

Plesmanlaan 121, 1066, CX, Amsterdam, The Netherlands

Full list of author information is available at the end of the article
}

(c) The Author(s). 2019 Open Access This article is distributed under the terms of the Creative Commons Attribution 4.0 International License (http://creativecommons.org/licenses/by/4.0/), which permits unrestricted use, distribution, and reproduction in any medium, provided you give appropriate credit to the original author(s) and the source, provide a link to the Creative Commons license, and indicate if changes were made. The Creative Commons Public Domain Dedication waiver (http://creativecommons.org/publicdomain/zero/1.0/) applies to the data made available in this article, unless otherwise stated. 


\section{Background}

Radical radiotherapy is widely used in patients with advanced solid tumours to achieve long-term locoregional control, translating into improvements in disease free and overall survival. The addition of chemotherapy has improved these outcomes in a broad range of tumour types [1]. Nevertheless, further improvements are warranted given both the toxicities of such radical treatments and the incidence of locoregional recurrences, especially as curative treatment options for recurrences are often limited. Dose escalation of radiotherapy and/or chemotherapy, however, is often limited by normal tissue toxicity. In addition, most radiosensitisers need to be applied intravenously, which is unpractical and invasive. Oral therapy would overcome these limitations.

Tumour specific radiosensitisers are expected to enhance tumour control without concomitantly increasing normal tissue toxicity. Potential tumour-specific radiosensitisers that are very promising in pre-clinical models include Poly (ADP-Ribose) Polymerase (PARP) inhibitors [2-4]. In patients the tolerability of PARP inhibitors as single agent compares favourably to most chemotherapeutic agents including cisplatin, currently the most widely used radiosensitiser in clinic [5-8]. Despite these promising characteristics of PARP inhibitors, little is known about the clinical value of PARP inhibitors as radiosensitisers [3].

PARP inhibitors are thought to radiosensitise through several different mechanisms. The best studied mechanism is through the inhibition of PARP1-mediated repair of radiation induced DNA damage. Other studies highlight the PARP1 trapping activity of such inhibitors that could interfere with cellular replication [9]. Radiosensitisation is more pronounced in replicating cells [10-13] and in cells that are homologous recombination deficient $[10,14,15]$. As both these properties are found more frequently in tumour cells compared to surrounding normal tissue cells, radiosensitisation is expected to occur preferentially in tumour cells. A second potential mechanism of tumourspecific radiosensitisation is based on the increase of tumour blood flow. Vessel dilation by several PARP inhibitors including olaparib increases tumour perfusion [1620]. This efficiently reduces the hypoxic, radioresistant fraction in the tumour rendering the overall tumour more sensitive to radiation. It may also improve drug delivery leading to chemosensitisation.

In clinic, several orally bioavailable PARP inhibitors are used as standard of care or being developed. No clinical data on any PARP inhibitor in combination with radiotherapy was available at the time of the design of our combination trials. To date several trials have been published that assessed the tolerability of the PARP inhibitor veliparib in combination with radiotherapy.
Radiotherapy in these combination trials was delivered to the whole abdomen [21, 22], the brain [23-27], the pelvic area for locally advanced rectal cancer [28] and the chest wall and regional lymph node areas for inflammatory or locoregionally recurrent breast cancer [29]. Haematological toxicity impeded the determination of a tolerable dose of veliparib in a triple treatment combination with radiation and temozolomide for glioblastoma multiforme [25]. All other trials found an acceptable safety profile of the combination treatment and identified a maximum tolerated dose (MTD) varying from 50 $\mathrm{mg}$ bi-daily to $400 \mathrm{mg}$ bi-daily. Dose limiting toxicities (DLTs) included nausea and vomiting [27, 28], radiation dermatitis [28] and fibrosis [29]. A recent study reports the results of a phase 1 trial that combines the PARP inhibitor olaparib with cetuximab and radiotherapy for locally advanced head and neck squamous cell carcinoma (HNSCC) [30]. The recommended phase 2 dose of olaparib in this combination treatment was established at $25 \mathrm{mg}$ bi-daily in tablet formulation. Dose limiting toxicity included dermatitis and nausea and vomiting. Grade 3-4 radiation dermatitis and mucositis were common (38 and 69\% respectively). Awaiting results, the PARADIGM-2 study and OLA-TMZ-RTE-01 trial investigate the safety and tolerability of olaparib and radiotherapy with and without temozolomide in glioblastoma $[31,32]$. To the best of our knowledge, there are no other published trial results on the combination of radiotherapy with olaparib.

To assess the clinical tolerability and safety of olaparib in combination with radiotherapy, we initiated three phase 1 trials in parallel: in patients with non-small cell lung cancer (NSCLC), breast cancer and HNSCC. Table 1 provides the rationales for the PARP inhibitor combination with radiotherapy in these specific types of cancer. All trials are investigator-initiated and single institution (The Netherlands Cancer Institute, the Netherlands). Olaparib is dose escalated in combination with a fixed radical (chemo-)radiotherapy regime in all trials to identify the MTD of olaparib in that specific combination treatment.

\section{Methods}

\section{Inclusion criteria}

The NSCLC trial includes patients in two parallel dose escalating arms. Patients can be included in the concurrent chemoradiotherapy (CCRT) arm if they have stage II/III inoperable disease without malignant pleural effusion. Patients can be included in the (sequential chemo-)radiotherapy ((SC)RT) arm if they have an indication for radical locoregional radiotherapy and, in case induction chemotherapy is given, if they have no disease progression after induction chemotherapy. This allows the inclusion of patients 


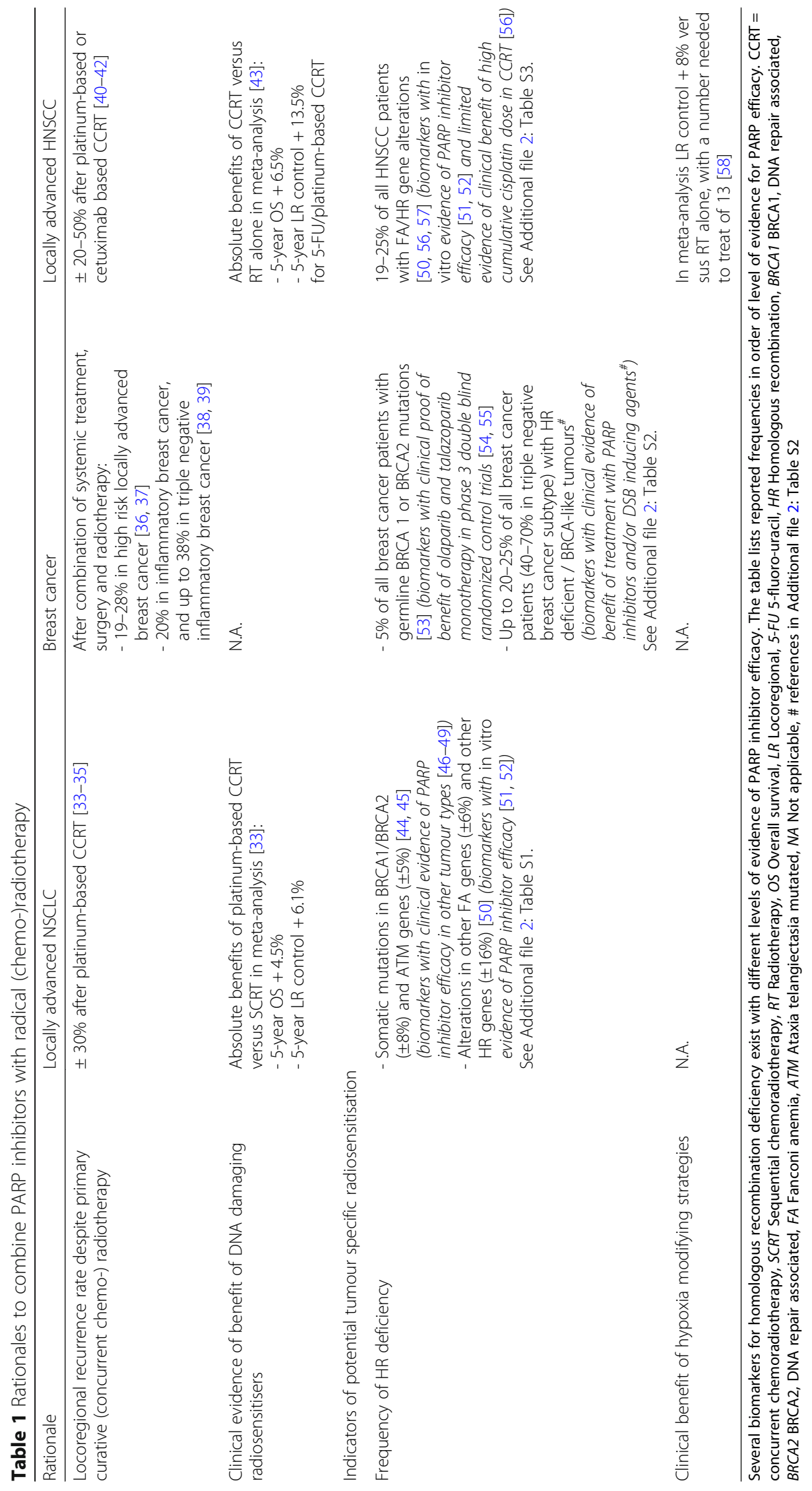


with oligometastatic disease with a good response to chemotherapy in the (SC) RT arm only [59].

The breast cancer trial includes patients with primary breast cancer or a local recurrence of breast cancer, including inflammatory breast cancer, which is inoperable and/or metastatic and that have an indication for breast irradiation. Patients with tumour involvement of the skin are included in a trial arm in which bolus material is used. Patients without tumour involvement of the skin are included in a parallel trial arm in which no bolus material is used. Concomitant use of tamoxifen or an aromatase inhibitor is allowed. Other systemic anti-cancer treatments are not allowed during the trial and up to four weeks after the last dose of olaparib.

The HNSCC trial includes patients with squamous cell carcinoma of the larynx (T2N0M0 or T1-2 N1-2bM0 or patients with locally advanced disease who will not receive CCRT) or oropharynx (T1-2 N1-2bM0 or T3 N0-2bM0 or patients with locally advanced disease who will not receive CCRT). Only oropharyngeal carcinoma patients with a HPV negative tumour status or oropharyngeal carcinoma patients with a history of smoking $\geq$ ten pack-years can be included (i.e. are at intermediate risk [60]).

Additional inclusion criteria in all three trials include: age higher than or equal to 18 years, a WHO performance status of $0-1$ (a performance status of 2 is also allowed in the breast cancer trial only), a life expectancy of at least six months, adequate haematological, renal and hepatic functions, no concurrent active malignancy (other than non-melanoma skin cancer or carcinoma-insitu), no prior radiotherapy to the involved region, no prior PARP inhibitor treatment, no concurrent CYP3A4 inhibitors of the following classes: azole antifungals, macrolide antibiotics, protease inhibitors and no gastrointestinal disorders that may interfere with absorption of the study drug.

\section{Study objectives and endpoints}

The primary objective of all three trials is to identify the maximum tolerated dose (MTD) of olaparib in combination with radical radiotherapy. The highest dose level at which not more than $15 \%$ of patients experience dose limiting toxicity (DLT) or the highest reached dose level in the absence of DLT is defined as the MTD. The primary endpoint is the incidence of DLT. DLT is defined separately in each trial. We differentiate DLT definition between the acute toxicity phase (i.e. until three months after end of study treatment) and late toxicity phase (i.e. from three months until one year after end of study treatment) (Table 2). We aimed to define DLT so that it would not exceed a 'baseline' incidence of $10 \%$ after (chemo-)radiotherapy without olaparib.
Secondary objectives are:

- to describe the safety profile of olaparib in combination with radical radiotherapy

- to determine the pharmacokinetic profile of olaparib

- to assess the pharmacodynamic effects of olaparib

- to document preliminary evidence of anti-tumour effects.

Translational research within the trials has the exploratory objective to investigate the potential and feasibility of biomarkers in whole blood, serum and tumour biopsy samples as surrogate and/or predictive biomarkers for anti-tumour effects and/or treatment related toxicities.

\section{Study treatment}

(Chemo-)radiation treatment details are summarised in Table 3. Radiation is delivered using IMRT (NSCLC, breast cancer) or VMAT-techniques (HNSCC). Following institutional guidelines, simultaneously integrated boost (SIB) and sequential boost techniques can be applied in the HNSCC trial. In the breast cancer trial, a boost to the macroscopic tumour in the breast is delivered using a SIB technique. Patients in the breast cancer trial with tumour involvement of the skin are irradiated using a skin bolus. Dose constraints to organs at risk follow institutional guidelines. Because of concerns of potentially increased risks of pneumonitis, for the first three patients in the NSCLC trial the maximal mean lung dose constraint is $16 \mathrm{~Gy}$ instead of the maximal 20Gy accepted in institutional guidelines.

Olaparib is taken orally twice daily with a 12 -h interval, starting two days before the first fraction of radiotherapy, continuing during weekends, until two days after the last fraction of radiotherapy. No specific time interval between radiation and olaparib intake is defined. To allow for translational research, olaparib is also given ahead of the combination treatment in two trials: two weeks before start of radiotherapy to take tumour biopsies in the breast cancer trial and one week before start of radiotherapy to acquire an extra MRI in the HNSCC trial. Figure 1 describes treatment schedules. Pre-defined dose levels are $25 \mathrm{mg}$ once daily, $25 \mathrm{mg}$ bi-daily, $50 \mathrm{mg}$ bi-daily, $100 \mathrm{mg}$ bi-daily, $200 \mathrm{mg}$ bi-daily and $300 \mathrm{mg}$ bidaily. Olaparib is given in tablet formulation. Olaparib 25 mg once daily is a predefined dose de-escalation level, see Additional file 1 for details. The starting dose level is olaparib $50 \mathrm{mg}$ bi-daily in the breast cancer trial arm without the use of a skin bolus and $25 \mathrm{mg}$ bi-daily in all other trial arms. These are relatively low doses compared to the recommended monotherapy dose (300 mg bi-daily in tablet formulation [62]). We chose these as our preclinical data showed radiosensitisation at 
Table 2 Definition of dose limiting toxicities in all three study protocols

\begin{tabular}{|c|c|c|c|c|}
\hline & NSCLC trial & Breast cancer trial & HNSCC trial & All three trials \\
\hline $\begin{array}{l}\text { Acute } \\
\text { toxicity } \\
\text { phase }\end{array}$ & $\begin{array}{l}\text { Non-hematological toxicity: } \\
\text { - Radiation pneumonitis gr } \geq 3 \\
\text { - Any other non-hematological gr } \geq 3 \\
\text { toxicity (other than radiation } \\
\text { esophagitis/dysphagia, radiation } \\
\text { dermatitis, fatigue, nausea and } \\
\text { vomiting, weight loss, anorexia and } \\
\text { dehydration) } \\
\text { - Gr } \geq 4 \text { radiation esophagitis/dysphagia, } \\
\text { radiation dermatitis, fatigue, nausea and } \\
\text { vomiting, weight loss, anorexia and } \\
\text { dehydration in the presence of } \\
\text { maximal support/treatment. } \\
\text { - Gr } 3 \text { radiation dermatitis present } \geq 9 \\
\text { weeks after end of treatment } \\
\text { - Gr } 2 \text { cardiac or neurological toxicity } \\
\text { Treatment discontinuation\#: } \\
\text { - Any radiotherapy discontinuation } \\
\text { - Cisplatin cumulative discontinuation for } \\
>20 \% \text { of the total prescribed dose }\end{array}$ & $\begin{array}{l}\text { Non-hematological toxicity: } \\
\text { - Radiation dermatitis gr } 4 \text { except if } \\
\text { this is associated with and at the } \\
\text { localization of the ulcerative tumour } \\
\text { - Radiation dermatitis gr } 3 \text { present } \geq 7 \\
\text { weeks after end of treatment } \\
\text { - Pain related to dermatitis } \mathrm{gr} \geq 3 \\
\text { present } \geq 7 \text { weeks after end of } \\
\text { treatment } \\
\text { - Edema breast gr } 3 \text { in the presence of } \\
\text { maximal support/treatment } \\
\text { - Nausea and vomiting gr } \geq 3 \text { in the } \\
\text { presence of maximal support/ } \\
\text { treatment } \\
\text { - Esophagitis gr } \geq 3 \\
\text { - Any other non-hematological toxicity } \\
\text { gr } \geq 3 \text { (except radiation dermatitis, } \\
\text { pain, edema, nausea, vomiting, } \\
\text { anorexia, weight loss and fatigue) } \\
\text { Treatment discontinuation: } \\
\text { - Any radiotherapy discontinuation } \\
\text { due to toxicity attributable to } \\
\text { radiotherapy, irrespective of the } \\
\text { grade of toxicity } \\
\text { - Cumulative discontinuation of } \\
\text { radiotherapy for }>5 \text { fractions due to } \\
\text { toxicity attributable to olaparib, } \\
\text { irrespective of the grade of toxicity }\end{array}$ & $\begin{array}{l}\text { Non-hematological } \\
\text { toxicity: } \\
\text { - Gr } \geq 4 \text { mucositis, } \\
\text { dysphagia, radiation } \\
\text { dermatitis, anorexia } \\
\text { - Gr } \geq 3 \text { hemorrhage, } \\
\text { aspiration, trismus } \\
\text { - Gr } \geq 3 \text { radiation } \\
\text { dermatitis present } \geq 8 \\
\text { weeks after end of } \\
\text { treatment } \\
\text { - Gr } \geq 3 \text { nausea and/or } \\
\text { vomiting in the presence } \\
\text { of maximal support } \\
\text { - Only in patients with } \\
\text { oropharynx SCC: gr } \geq 3 \\
\text { larynx edema } \\
\text { - Weight loss } \geq 20 \% \text { of } \\
\text { baseline weight } \\
\text { Treatment } \\
\text { discontinuation }{ }^{\#} \text { : } \\
\text { - Cumulative } \\
\text { discontinuation of } \\
\text { radiotherapy for }>3 \\
\text { fractions }\end{array}$ & $\begin{array}{l}\text { Hematological toxicity: } \\
\text { - Neutropenia gr } 4 \text { lasting } \\
\text { for }>6 \text { days } \\
\text { - Neutropenic fever gr } \geq 3 \\
\text { - Thrombocytopenia gr } 3 \text { in } \\
\text { the presence of bleeding; } \\
\text { Thrombocytopenia gr } \geq 4 \\
\text { - Anemia gr } 3 \text { in the } \\
\text { presence of blood } \\
\text { transfusion dependency } \\
\text { as judged by the Pl; } \\
\text { Anemia gr } \geq 4 \\
\text { Other: } \\
\text { - Any other toxicity, which } \\
\text { in the judgment of the } \\
\text { Investigator is viewed as } \\
\text { DLT } \\
\text { Treatment discontinuation" } \\
\text { - Olaparib total } \\
\text { discontinuation for }>20 \% \\
\text { of the total prescribed } \\
\text { dose }\end{array}$ \\
\hline $\begin{array}{l}\text { Late } \\
\text { toxicity } \\
\text { phase }\end{array}$ & $\begin{array}{l}\text { Non-hematological toxicity: } \\
\text { - Gr } \geq 3 \text { radiation pneumonitis, brachial } \\
\text { plexopathy, esophageal stenosis, } \\
\text { esophageal ulcer, esophageal necrosis, } \\
\text { esophageal hemorrhage } \\
\text { - Gr } \geq 2 \text { myelitis, esophageal perforation, } \\
\text { esophageal fistula }\end{array}$ & $\begin{array}{l}\text { Non-hematological toxicity: } \\
\text { - Fibrosis gr } \geq 3 \text { outside the boost field } \\
\text { AND if applicable outside the skin } \\
\text { bolus field } \\
\text { - Skin ulceration gr } \geq 2 \text { except if this is } \\
\text { persisting acute toxicity associated } \\
\text { with and at the localisation of the } \\
\text { ulcerative tumour } \\
\text { - Radiation pneumonitis gr } \geq 3 \\
\text { - Esophagitis gr } \geq 3 \\
\text { - Brachial plexopathy gr } \geq 2 \text { except if } \\
\text { there was pre-existing brachial } \\
\text { plexopathy or if the brachial } \\
\text { plexopathy is tumour progression } \\
\text { related }\end{array}$ & $\begin{array}{l}\text { Non-hematological } \\
\text { toxicity: } \\
\text { - Gr } \geq 4 \text { dysphagia, } \\
\text { aspiration } \\
\text { - Gr } \geq 3 \text { hemorrhage, skin } \\
\text { atrophy, trismus, } \\
\text { osteoradionecrosis, } \\
\text { radiation dermatitis, } \\
\text { pneumonitis } \\
\text { - Gr } \geq 2 \text { fistula, myelitis } \\
\text { - Gr } \geq 2 \text { mucosal ulcer } \\
\text { present } \geq 6 \text { months after } \\
\text { end of treatment } \\
\text { - Fibrosis limiting joint or } \\
\text { orifice movement (e.g. } \\
\text { mouth) and/or limiting } \\
\text { self-care ADL } \\
\text { - Only in patients with } \\
\text { oropharynx SCC: gr } \geq 3 \\
\text { larynx stenosis }\end{array}$ & $\begin{array}{l}\text { Hematological toxicity: } \\
\text { - Blood transfusion } \\
\text { dependency as judged by } \\
\text { the PI, unless the patient } \\
\text { has progressive disease } \\
\text { - Development of MDS/ } \\
\text { AML } \\
\text { Other: } \\
\text { - Any other toxicity, which } \\
\text { in the judgment of the } \\
\text { Investigator is viewed as } \\
\text { DLT }\end{array}$ \\
\hline
\end{tabular}

The acute and late toxicity phases are defined as between start of treatment until three months after end of study treatment, and between three months until one year after end of study treatment respectively. All toxicities are graded according to CTCAE version 4.03 and are only considered a dose limiting toxicity (DLT) if they are assessed by the investigator as possibly, probably or definitely related to the combination of radiotherapy and olaparib. \# Treatment discontinuation can be intermittent and/or continuous and is only considered a DLT if this is due to toxicity attributable to the combination study treatment, irrespective of the grade of toxicity. $\mathrm{Gr}=$ grade, $\mathrm{ADL}=$ activity of daily living, $\mathrm{SCC}=$ squamous cell carcinoma, $\mathrm{MDS}=$ myelodysplastic syndrome, $\mathrm{AML}=$ acute myeloid leukemia

significantly lower olaparib concentrations than required for monotherapy efficacy [14]. Considering the available patient pharmacokinetic data [62] and dependence on the genetic tumour background one could expect radiosensitisation around $25 \mathrm{mg}$ olaparib dose (tablet formulation) with an dose enhancement factor between 1.2 and 1.6 [14]. The starting dose level in the breast cancer trial arm without the use of a skin bolus is higher as the incidence, severity and duration of expected dose limiting toxicity such as dermatitis and mucositis is lower.

\section{Dose escalation design}

The expected incidence, duration and severity of toxicities strongly depend on the use of a skin bolus (breast cancer trial) and on the use of concurrent chemotherapy (NSCLC trial). Therefore, olaparib is dose escalated separately in patients with and without the use of a skin bolus or concomitant chemotherapy. This results in two parallel study arms in the NSCLC trial and in the breast cancer trial, and only one trial arm in the HNSCC trial. As a consequence, the identified MTD can differ not 
Table 3 (Chemo-)radiation treatment details

\begin{tabular}{|c|c|c|c|c|}
\hline & Radiation target volumes & Radiation dose & Boost / Elective fields & Chemotherapy \\
\hline NSCLC trial & $\begin{array}{l}\text { Primary lung tumour and involved } \\
\text { regional lymph nodes }\end{array}$ & 66 Gy in 24 fractions & N.A. & $\begin{array}{l}\text { Cisplatin } 6 \mathrm{mg} / \mathrm{m}^{2} 1.5-2 \mathrm{r} \\
\text { before radiation on every } \\
\text { radiotherapy day }{ }^{\#}\end{array}$ \\
\hline Breast cancer trial & $\begin{array}{l}\text { Whole breast and involved regional } \\
\text { lymph node areas }\end{array}$ & $\begin{array}{l}46.69 \text { Gy in } 23 \\
\text { fractions }\end{array}$ & $\begin{array}{l}\text { SIB of } 14.49 \text { Gy in } 23 \text { fractions to } \\
\text { macroscopic tumour in breast; } \\
\text { sequential boost of } 10 \text { Gy in } 5 \\
\text { fractions to macroscopic lymph } \\
\text { nodes (only if applicable) }\end{array}$ & N.A. \\
\hline HNSCC trial & $\begin{array}{l}\text { Primary tumour and regional metastatic } \\
\text { lymph nodes; elective lymph node } \\
\text { volumes based on site of primary } \\
\text { tumour and stage }\end{array}$ & 70 Gy in 35 fractions & $\begin{array}{l}\text { Elective fields: } 46 \text { Gy in } 23 \text { fractions } \\
\text { (sequential boost technique) or } \\
54.25 \text { Gy in } 35 \text { fractions (SIB technique) }\end{array}$ & N.A. \\
\hline
\end{tabular}

\# in the CCRT arm only. Gy= Gray. N.A. = not applicable, SIB = simultaneous integrated boost

only between trials but also between the two study arms within the same trial. Each trial arm accrues an estimated maximum of 36 patients evaluable for DLTs.

The NSCLC trial was launched first and started with a standard $3+3$ design [63]. However, to be able to include late onset toxicity in the DLT definition, the dose escalation method was switched to a Time-to-Event Continual Reassessment Method (TITE-CRM [64, 65]). The breast cancer trial and HNSCC trial directly started with a TITE-CRM design. TITE-CRM is recommended for radiotherapy studies in several guidelines as late onset toxicity can be dose limiting [1, 66-68]. In short, TITE-CRM uses a dose level - toxicity model to identify the MTD, thereby weighting patients according to their time of follow-up. It allows the trial to continue with patient enrolment while previous patients are still being evaluated for late onset DLT. The first three patients in each trial arm are treated at the starting dose level. Thereafter, patients are assigned to a dose level using TITE-CRM and dose escalation rules. Upon enrolment of a new patient, TITE-CRM estimates the current MTD (see statistical analysis). New patients are assigned to the dose level that is closest to but not exceeding this current estimated MTD after applying two restrictive dose-escalation rules: 1) at least three patients have completed a minimal follow-up time of three months after end of treatment at the dose level below the assigned dose level, and 2) the assigned dose level may not increase more than one dose level between two consecutive patients. There is no restriction on the decrease in number of levels between consecutive patients.

\section{Assessments}

Toxicity is assessed using the common terminology criteria for adverse events (CTCAE) version 4.03 at baseline, weekly during treatment, five times during the acute toxicity phase and at all follow-up visits during the late toxicity phase. The frequency and duration of follow-up visits in the late toxicity phase differs between trials: three monthly until two years after end of treatment (EOT) in the breast cancer trial, three monthly until one year after EOT and six monthly between one and five years after EOT in the NSCLC trial, and two monthly until one year after EOT and three monthly

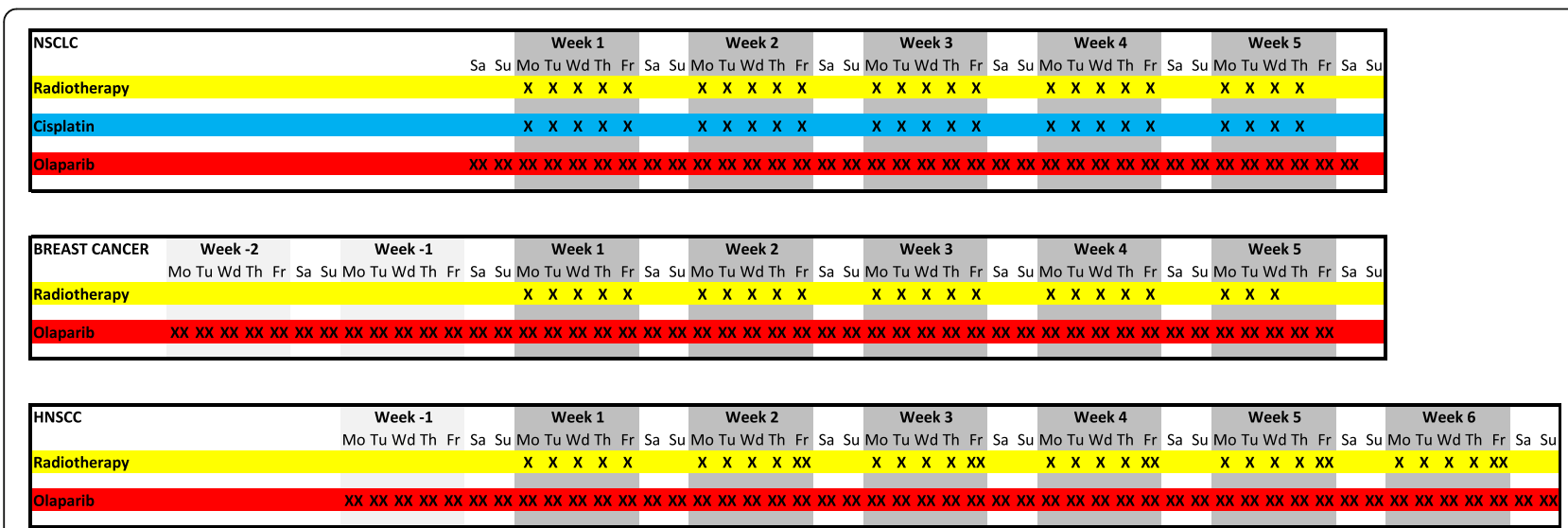

Fig. 1 Treatment schedules in the NSCLC, breast cancer and HNSCC trials. Cisplatin is only given to patients in the CCRT arm. Radiotherapy in the HNSCC trial is delivered in five to six fractions per week in six weeks, the sixth fraction will be given on a weekday with an interval of at least six hours [61] 
between one and two years after EOT in the HNSCC trial. Patients in all trials are followed until the last planned study follow-up visit or until disease progression, whichever occurs first. There is one exception, if disease progression occurs within the first year after EOT, toxicity assessments are completed until one year after EOT to be able to fully assess the DLT incidence. To evaluate cosmetic outcome in the breast cancer trial, breast appearance of the irradiated breast is scored according to Harvard criteria [69] at baseline and threemonthly until two years after EOT. Additionally, clinical photographs are taken at baseline, one week, three months and one year after EOT.

Treatment response is assessed using a tailored method in each trial: using a chest CT and FDG PETCT scan six weeks after treatment in the NSCLC trial, using a prone breast-MRI three months after treatment in the breast cancer trial and a CT (only in case of larynx carcinoma) and MRI of the head and neck region three months after treatment in the HNSCC trial. Additional treatment response assessments at later time points are defined in the study protocols and follow institutional guidelines.

\section{Translational research}

The primary purpose of translational research studies included in these trials is to investigate the biologically effective dose range of olaparib in combination with radiotherapy. It has been shown that much lower olaparib concentrations than those causing single agent cytotoxicity are required to be effective as radiosensitiser [14]. To investigate the biologically effective dose range of olaparib in patients, pharmacokinetic (PK) and adapted pharmacodynamic (PD) studies are conducted. Patient material is collected at several time points for these PK/PD studies. Plasma samples for PK analysis are taken on the day of the fourth radiation fraction (i.e. at near steady state olaparib levels [70]) at several time points in all trials: before olaparib intake and $0.5,1,2,3$, 4, 6, 8 and $12 \mathrm{~h}$ after intake. Blood samples are taken for PD analysis in all trials before start of treatment, several times during study treatment at three hours after olaparib intake and shortly before the next olaparib intake, and after end of treatment. An additional plasma sample is taken at each of these time points to assess PK-PD relationships. The collection of tumour biopsy material is restricted to the breast cancer trial and planned both before the start of treatment and at three hours after olaparib intake during the olaparib pre-treatment phase (week -1 in Fig. 1).

Olaparib concentrations are measured in plasma and tumour samples using a validated high-performance liquid chromatography-tandem mass spectrometry (HPLC-MS/ MS) method [71]. Pharmacodynamic analyses primarily focus on biological effective target inhibition in the context of radiation-induced responses, in this case radiationinduced PARylation. PAR levels are measured using our previously reported modified 'REP-assay' (radiation-enhanced-PAR-assay [72]). This ELISA-based PD assay includes an ex vivo irradiation step of intact cells to activate PARylation by PARP. The assay's sensitivity to detect PARP inhibition was greatly increased by this modification and revealed inhibition of radiation-induced PARylation at low olaparib concentrations in a healthy volunteer study [72]. In our trials, the inhibition of radiation-induced PAR levels is assessed both in peripheral blood mononuclear cells from all trial patients, and in tumour biopsy material from breast cancer trial patients.

Another pharmacodynamic study aims to investigate the reported vasoactive properties of some PARP inhibiting compounds that alter tumour perfusion [16-20]. The associated reduction in tumour hypoxia and improvement in tumour drug delivery will be important determinants of response to radiotherapy and combined treatment. Tumour perfusion changes are therefore investigated by dynamic contrast enhanced MRIs in the HNSCC trial. MRI images are acquired in radiation mask before start of treatment and 1.5-2 h after olaparib intake during the olaparib pre-treatment phase (week 1 in Fig. 1). Furthermore, PARP inhibitors may impact healthy tissue toxicity by interfering in the inflammatory responses induced by radiotherapy. Repeated serum samples are taken before, during and after treatment for analyses of changes in markers related to the radiationinduced inflammatory response, such as TGF-beta [73, 74]. Additionally the feasibility and potential value of candidate response biomarkers for the combination treatment of olaparib and radiotherapy is investigated. Given the increased radiosensitisation in DNA damage repair defected tumours $[10,14,15]$ and in hypoxic tumours $[17,75]$, this includes biomarkers for DNA repair defects such as homologous recombination deficiency, and/or biomarkers for hypoxia. These additional genetic analyses are an optional part in the breast cancer trial and the HNSCC trial, of which patients are informed using a separate patient information file containing a separate form for consent.

\section{Treatment adherence and discontinuation}

Adherence to daily oral olaparib intake is monitored closely. Actual drug intake is documented in a patient diary by patients themselves. A trained research nurse or radiation therapy technologist discusses olaparib intake and the patient diary completion before start of treatment and weekly until the end of treatment with each patient. Any discrepancies between returned tablets after end of treatment and documentation in the patient diary will be discussed with the patient. 
Olaparib will be permanently discontinued in patients in whom a dose limiting toxicity occurs during treatment. Cisplatin, if given, will be discontinued until improvement in case of $\geq 30 \%$ reduction of glomerular filtration rate (GFR), a GFR $<50 \mathrm{ml} / \mathrm{min}$ or thrombocytopenia $<75$ x 10E9/l. The decision to interrupt or change the radiotherapy regimen will be made on a case by case basis. In general radiotherapy will be continued in case of toxicity that can clearly be ascribed to olaparib or cisplatin, or in case only a limited number of radiotherapy fractions have to be delivered. In case of study treatment discontinuation after less than $80 \%$ of the planned cumulative olaparib dose, patients will have follow-up of all adverse events until resolution or until three months after the last dose of olaparib, whichever occurs first. In case of study treatment discontinuation after more than $80 \%$ of the planned cumulative olaparib dose, patients will undergo all planned study assessments.

\section{Serious adverse events}

Serious adverse events (SAE) are defined according to the rules of Good Clinical Practice. All SAEs occurring until three months after end of study treatment must be reported. Thereafter, only possibly, probably or definitively related SAEs must be reported until the last study follow-up visit (see assessments). The above specified SAEs must be reported within one working day and are listed in an annually safety report.

\section{Data management and monitoring}

Data will be collected on Case Report Forms and will be entered in database at the Department of Biometrics. Data cleaning will be performed following a study specific central data management plan. Source data verification will be performed by an independent Clinical Research Monitor. The study is considered to be high risk according to guidelines of the Dutch Federation of University Medical Centres. Therefore, $100 \%$ of all data will be monitored in the first three patients, and 100\% of all primary data will be monitored in all subsequent patients. Drug-accountability will be performed by both the Clinical Research Monitor and Slotervaart Pharmacy. An auditing trial will not be performed routinely. All study results will be processed anonymously, identified by a patient verification code. All study files will be stored for 15 years.

\section{Statistical analysis}

TITE-CRM uses a one parameter power model calculating the probability $P$ of a DLT for a given dose $d$ with the following formula: $P(\mathrm{DLT} / \mathrm{d})=\mathrm{d} \exp \beta$. The dosetoxicity parameter $\beta$ is initially assumed to have a normal distribution with mean 0.0 and standard deviation of 1.16. Upon enrolment of a new patient, a new value of $\beta$ is calculated based on a prior estimated DLT probability and the observed DLT rate in all already enrolled patients. The weight $(\mathrm{w})$ of enrolled patients without DLT depends on their follow-up time according to a piecewise linear function which is $\mathrm{w}=0$ at start of treatment, $\mathrm{w}=0.5$ at three months after end of study treatment and $\mathrm{w}=1$ at one year after end of study treatment. This gives equal weight to the acute and late DLT periods. Patients experiencing a DLT are given the full weight $(\mathrm{w}=1)$ independent of the time of DLT appearance and follow-up time. Subsequently posterior DLT probabilities with $90 \%$ Bayesian confidence intervals ("credible intervals") are calculated for each dose level. The dose level that is closest to but not exceeding a $15 \%$ posterior DLT probability (i.e. the current estimated probability) is identified as the current estimated MTD. Once all patients in a trial arm completed their maximum DLT-observation period, this posterior DLT probability is the final estimate of the MTD. All calculations are performed at the statistical department of The Netherlands Cancer Institute using $\mathrm{R}$ software version 3.5.0 with package $\mathrm{dfcrm}$ version $0.2-2$ [76].

\section{Discussion}

The clinical development of radiosensitisers in a curative setting faces several important challenges [1, 66, 77]. First, concurrent chemotherapy regimens are often standard of care. Locally advanced NSCLC and locally advanced HNSCC are both treated with CCRT which is often cisplatin-based. Two clinical development strategies can be followed: one to compose a triple combination, or another to substitute the currently used chemotherapy by a novel radiosensitiser. The choice is based on the evaluation of expected efficacy, toxicity and feasibility. To the best of our knowledge, there are no preclinical data on a triple combination of radiation, cisplatin and a PARP inhibitor. Preclinical models have shown that PARP inhibitors not only sensitise tumours to radiation, but also to the well-established radiosensitiser cisplatin [78, 79]. Such triple treatments may therefore have strong anti-tumour effects. In clinic, nevertheless, other triple combinations did not always show superiority over the standard of care [40, 80, 81]. Also, triple combination treatments are often not welltolerated [40, 80]. Mucositis and haematological toxicity are expected to be dose limiting in a triple combination of radiotherapy, cisplatin and a PARP inhibitor. Radiation induced mucositis is increased by cisplatin [33, 82 , 83]. This could be aggravated by PARP inhibitors as both chemo- and radiosensitisation can occur especially in rapidly dividing tissue [10-13]). Haematological toxicity is shown to be dose limiting in a combination of olaparib and high dose cisplatin [84]. CCRT for HNSCC is given with a high dose of cisplatin and results in mucositis rates that are high and already close to dose 
limiting without a PARP inhibitor. We therefore reasoned that a triple combination in HNSCC would be too toxic. In the NSCLC trial, however, we decided to investigate the safety and tolerability of a triple combination treatment. Mucositis/esophagitis rates induced by cisplatin-based CCRT are substantially lower in NSCLC compared to HNSCC. Also, the lower cisplatin dose used in our CCRT schedule for NSCLC has a lower risk of haematological toxicity [85].

The second development strategy aims to substitute cisplatin by olaparib. Although a direct preclinical comparison of radiosensitisation potential between cisplatin and PARP inhibitors is lacking, reported radiation dose enhancement factors support a substitution strategy (i.e. around 1.2 for cisplatin [86] and 1.3-1.5 for PARP inhibitors $[3,14]$ in in vitro models). The substitution strategy is also supported by the favourable toxicity profile of PARP inhibitors. Systemic toxicity such as cisplatin induced nephrotoxicity will be avoided. Furthermore, olaparib has the advantages of being an oral drug over the intravenously injected cisplatin: non-invasive, more patient friendly and with less logistical issues. The challenge of the substitution strategy, however, concerns the identification of a large enough patient population for study inclusion. On the one hand, it is usually not considered acceptable to substitute a therapeutic agent for which level one clinical evidence of survival benefit exists (i.e. concurrent chemotherapy), with a therapeutic agent for which only preclinical evidence of radiosensitisation is available (i.e. in our trials olaparib). This possibly results in the 'under treatment' of patients. On the other hand, it is usually considered not justified to 'over treat' patients with metastatic disease with a radical radiotherapy regimen including a radiosensitiser that potentially even worsens toxicity. We defined our trial patient populations balancing between these ethical concerns. In the (SC) RT arm of the NSCLC trial we allow the inclusion of patients with oligometastatic disease, as their prognosis is comparable to that of patients with stage III disease in which the toxicity risks of radical radiotherapy are clinically accepted [59]. In the HNSCC trial we include patients with an intermediate risk for locoregional recurrence in whom standard of care treatment according to institutional policies is accelerated radiotherapy, only excluding HPV positive oropharyngeal tumours with a low risk of locoregional recurrence [60].

Another challenge in the clinical development of radiosensitisers concerns the strong dependency of toxicity profiles on radiation volumes and schedules $[1,66$, 77]. The safety and tolerability of a radiosensitiser is therefore likely to depend on these same variables. The MTD for a given radiosensitiser can differ between primary tumour sites and radiotherapy schedules, as is shown for e.g. gemcitabine [1] and veliparib [21-25, 2729]. Hence, we designed three parallel dose escalation trials. In addition, as the use of concurrent chemotherapy in NSCLC [33] or the use of a skin bolus in breast cancer [87-89] significantly increases toxicity, we designed parallel trial arms for separate dose escalation within the NSCLC trial and the breast cancer trial.

A final challenge in the clinical development of radiosensitisers concerns the DLT definition and evaluation period [1]. DLTs are typically defined as toxicities of grade three or more. In radical radiotherapy treatment regimens, however, certain grade three acute toxicities are common and considered clinically acceptable (e.g. dermatitis in the area where a skin bolus is used). In the case of such expected and accepted severe toxicities, DLTs can be defined as more severe than expected toxicity (e.g. grade four dermatitis) and/or as expected severe toxicity with a longer duration than expected (e.g. grade three dermatitis present $\geq$ seven weeks after end of treatment) [66]. A third strategy is to define a higher DLT probability as the MTD, taking a certain 'baseline' DLT probability with (chemo-)radiotherapy alone into account. We determined DLT definitions and acceptable DLT probabilities based on a structured literature review and expert opinions. The duration of the DLT evaluation period is also important, and can influence the final MTD dramatically. The MTD of veliparib in combination with radiotherapy to the chest wall and regional lymph node areas [29] was determined to be $200 \mathrm{mg}$ bi-daily based on acute toxicity only. However, after considering the late onset toxicity that only started to occur one year after end of treatment, the final MTD was determined to be $50 \mathrm{mg}$ bi-daily. Severe late onset toxicity was also found to appear six months after end of treatment in the recently published phase 1 trial combining olaparib with cetuximab and radiotherapy [30]. The MTD was based on acute toxicity only and determined to be $50 \mathrm{mg}$ bi-daily. However, the recommended phase 2 dose was established at 25 mg bi-daily. Our trials have a DLT evaluation period until one year after end of treatment, as this time window captures most of the late onset toxicity such as late (consequential) oesophagus toxicity [90] and radiation pneumonitis [91].

In summary, we present three parallel single institutional phase 1 trials in which the PARP inhibitor olaparib is dose escalated in combination with radical (chemo-)radiotherapy in NSCLC, breast cancer and HNSCC patients to assess safety and tolerability of the combination treatments. Through the tumour-specific radiosensitisation of PARP inhibitors, these combination treatments have the potential to improve patient outcomes, by achieving higher locoregional control rates and/or less treatment associated toxicity. 


\section{Additional files}

Additional file 1: De-escalation dose level. Treatment schedules of the predefined dose de-escalation level of olaparib $25 \mathrm{mg}$ once daily. (DOCX $69 \mathrm{~kb}$ )

Additional file 2: Tables S1-S3. Homologous recombination deficiency in NSCLC, breast cancer and HNSCC. The tables list reported gene mutation frequencies, if applicable BRCA-ness frequencies, and data showing preclinical and clinical PARP efficacy. (DOCX $147 \mathrm{~kb}$ )

\section{Abbreviations}

(SC)RT: (sequential chemo-)radiotherapy; 5-FU: 5-fluoro-uracil; ADL: activity of daily living; AML: acute myeloid leukemia; ATM: ataxia telangiectasia mutated; BRCA1: BRCA1, DNA repair associated; BRCA2: BRCA2, DNA repair associated; CCRT: concurrent chemoradiotherapy; CTCAE: common terminology criteria for adverse events; DLT: dose limiting toxicity; EOT: end of treatment; FA: fanconi anemia; GFR: glomerular filtration rate; gr: grade; Gy: Gray; HNSCC: head and neck squamous cell carcinoma; HPLC-MS/ MS: high performance liquid chromatography-tandem mass spectrometry; HPV: human papillomavirus; HR: homologous recombination; IMRT: intensity modulated radiation therapy; LR: locoregional; MDS: myelodysplastic syndrome; METC: Medisch-Ethische Toetsingscommissie (medical ethics committee); mg: milligram; MTD: maximum tolerated dose; NA: not applicable; NSCLC: non-small cell lung cancer; OS: overall survival; PARP: poly (ADP-ribose) polymerase; PBMCs: peripheral blood mononuclear cells; PD: pharmacodynamic; PK: pharmacokinetic; REP-assay: Radiation-EnhancedPAR assay; RT: radiotherapy; SCC: squamous cell carcinoma; SIB: simultaneous integrated boost; TITE-CRM: time-to-event continual reassessment method; VMAT: volumetric modulated arc therapy; w: weight

\section{Acknowledgements}

The authors acknowledge Abrahim Al-Mamgani, Judi van Diessen and Joop de Langen for their continuous efforts in the conduction of one of the trials described in this paper (AA in the HNSCC trial, JVD and JdL in the NSCLC trial).

\section{Authors' contributions}

$\mathrm{MV}, \mathrm{JS}, \mathrm{CV}, \mathrm{BV} T$ and $\mathrm{RdH}$ are principle members of the 'olaparib radiotherapy study team' at The Netherlands Cancer Institute, and contributed substantially to the design of the study protocols. MvdH and HP contributed substantially to the design of the NSCLC trial, GS and PE contributed substantially to the design of the breast cancer trial, MvdB and MT contributed substantially to the design of the HNSCC trial. EvW implemented the TITE-CRM methodology. RdH wrote this manuscript. All authors read and approved the final manuscript.

\section{Authors' information}

MV is professor and until August 1st, 2018 the head of the Department of Radiation Oncology at The Netherlands Cancer Institute, Amsterdam, The Netherlands, and currently head of the Department of Radiation Oncology at Radboud University Medical Center, Nijmegen, The Netherlands. MvdH is professor and head of the Department of Lung Diseases at Radboud University Medical Center, Nijmegen, The Netherlands. MvdB is professor and head and neck surgeon. CV is radiobiologist. JS is professor and until July 1st, 2018 the head of the Department of Clinical Pharmacology at The Netherlands Cancer Institute, Amsterdam, The Netherlands. HP is dedicated lung radiation oncologist, $\mathrm{PE}$ is dedicated breast cancer radiation oncologist. GS is dedicated breast cancer medical oncologist, MT is dedicated HNSCC medical oncologist and AA is dedicated HNSCC radiation oncologist. EvW is statistician. $\mathrm{RdH}$ is resident in radiation oncology and $\mathrm{PhD}$ student. BVT is radiation oncologist with a special interest in the development of radiosensitisers. All authors worked at The Netherlands Cancer Institute, Amsterdam, The Netherlands at the time of the design of the three study protocol described in this article.

\section{Funding}

The primary sponsor of the trials is the Netherlands Cancer Institute. AstraZeneca provided olaparib free of charge for the patients included in the trials and provided a grant to support the trials. AstraZeneca had no role in the design of this study and will not have any role during its execution, analyses, interpretation of the data, or decision to submit results.

\section{Availability of data and materials}

Not applicable.

\section{Ethics approval and consent to participate}

All studies will be performed compliant with current standards of ICH GCP, the WHO Declaration of Helsinki and in accordance with the Medical Research Involving Human Subjects Act (WMO). The study protocols of all three trials are approved by the METC (Medisch-Ethische Toetsingscommissie, medical ethics committee) of The Netherlands Cancer Institute, Amsterdam, The Netherlands. All past and future protocol modifications are, or will be, submitted as amendments to the METC for approval. Most recent approved protocol versions are: version 6.0 dated June 23, 2014 for the NSCLC trial, version 6.0 dated March 08, 2017 for the breast cancer trial, and version 5.0 dated March 28, 2018 for the HNSCC trial. Patients receive both oral and written information on the study from their treating physician. Written informed consent is obtained before any study procedures. An optional part in the breast cancer trial and HNSCC trial involves genetic analysis. For patients that choose to take part of this analysis, there is a possibility of detection of unsolicited findings, i.e. germline DNA variants that confer an increased risk of developing malignancies or other diseases for both the patient and his/her family. Patients are informed about this possibility, and will be offered genetic counseling in case of revelation of a variant which is clinically relevant. A separate patient information file and consent form is used for this optional part of the study. Genetic analysis will only be performed in patients that give consent to performing genetic analysis AND to being informed on any unsolicited findings with clinical significance that have direct consequences for treatment or that are directly actionable (e.g. pathogenic mutations in BRCA1/2 genes). Patients can choose to be informed on unsolicited findings with clinical significance that are not directly actionable (e.g. carrier of an autosomal recessive disease). The complete study team at The Netherlands Cancer Institute will have access to the final trial dataset. The Netherlands Cancer Institute has a liability insurance that provides cover for damage to research subjects through injury or death as a result of participation in either one of the described studies. Trial results will be published in a major, peerreviewed journal. Co-authors will include members of the protocol writing committee and physicians that have a substantial contribution in the conduct of the trial. AstraZeneca will be provided draft copies of all publications to review one month before submission. ClinicalTrials.gov registration was done on March 23, 2012 for the NSCLC trial, on August 27, 2014 for the breast cancer trial, and on September 1, 2014 for the HNSCC trial. The first patient was enrolled at June 06, 2012 in the NSCLC trial, at October 21, 2013 in the breast cancer trial, and at September 09, 2014 in the HNSCC trial. All three trials are currently ongoing. Secondary identifying trial numbers are:

o NSCLC trial: 2011-001289-16 (EudraCT), NL35195.031.11 (CCMO)

- Breast cancer trial: 2011-001586-40 (EudraCT), NL36278.031.13 (CCMO)

o HNSCC trial: 2011-002963-79 (EudraCT), NL38482.031.13 (CCMO)

\section{Consent for publication}

Not applicable.

\section{Competing interests}

JS, MV and CV filed a patent for the 'REP-assay' used in the trials. GS receives institutional research support from AstraZeneca and Merck. MvdH receives institutional research support from AstraZeneca.

\section{Author details}

${ }^{1}$ Department of Radiation Oncology, The Netherlands Cancer Institute, Plesmanlaan 121, 1066, CX, Amsterdam, The Netherlands. ${ }^{2}$ Department of Biometrics, The Netherlands Cancer Institute, Plesmanlaan 121, 1066, CX, Amsterdam, The Netherlands. ${ }^{3}$ Department of Thoracic Oncology, The Netherlands Cancer Institute, Plesmanlaan 121, Amsterdam 1066, CX, The Netherlands. ${ }^{4}$ Department of Medical Oncology, The Netherlands Cancer Institute, Plesmanlaan 121, 1066, CX, Amsterdam, The Netherlands. ${ }^{5}$ Department of Head and Neck Surgery and Oncology, The Netherlands Cancer Institute, Plesmanlaan 121, 1066, CX, Amsterdam, The Netherlands. ${ }^{6}$ Division of Cell Biology, The Netherlands Cancer Institute, Plesmanlaan 121, 1066, CX, Amsterdam, The Netherlands. ${ }^{7}$ Division of Pharmacology, The Netherlands Cancer Institute, Plesmanlaan 121, 1066, CX, Amsterdam, The 
Netherlands. ${ }^{8}$ Department of Pharmaceutical Sciences, Utrecht University, Utrecht, The Netherlands.

\section{Received: 27 November 2018 Accepted: 2 September 2019} Published online: 10 September 2019

\section{References}

1. Lawrence YR, Vikram B, Dignam JJ, Chakravarti A, Machtay M, Freidlin B, Takebe N, Curran WJ Jr, Bentzen SM, Okunieff P, et al. NCI-RTOG translational program strategic guidelines for the early-stage development of radiosensitizers. J Natl Cancer Inst. 2013;105:1.

2. Chalmers AJ, Lakshman M, Chan N, Bristow RG. Poly (ADP-ribose) polymerase inhibition as a model for synthetic lethality in developing radiation oncology targets. Semin Radiat Oncol. 2010;20:4.

3. Lesueur P, Chevalier F, Austry JB, Waissi W, Burckel H, Noel G, Habrand JL, Saintigny $Y$, Joly F. Poly-(ADP-ribose)-polymerase inhibitors as radiosensitizers: a systematic review of pre-clinical and clinical human studies. Oncotarget. 2017:8:40.

4. Powell C, Mikropoulos C, Kaye SB, Nutting CM, Bhide SA, Newbold K, Harrington KJ. Pre-clinical and clinical evaluation of PARP inhibitors as tumour-specific radiosensitisers. Cancer Treat Rev. 2010;36:7.

5. Audeh MW, Carmichael J, Penson RT, Friedlander M, Powell B, Bell-McGuinn KM, Scott C, Weitzel JN, Oaknin A, Loman N, et al. Oral poly (ADP-ribose) polymerase inhibitor olaparib in patients with BRCA1 or BRCA2 mutations and recurrent ovarian cancer: a proof-of-concept trial. Lancet. 2010;376:9737.

6. Fong PC, Boss DS, Yap TA, Tutt AN, Wu P, Mergui-Roelvink M, Mortimer P, Swaisland H, Lau A, O'Connor MJ, et al. Inhibition of poly (ADPribose) polymerase in tumors from BRCA mutation carriers. N Engl J Med. 2009:361:2

7. Ledermann J, Harter P, Gourley C, Friedlander M, Vergote I, Rustin G, Scott C, Meier W, Shapira-Frommer R, Safra T, et al. Olaparib maintenance therapy in platinum-sensitive relapsed ovarian cancer. N Engl J Med. 2012;366:15

8. Tutt A, Robson M, Garber JE, Domchek SM, Audeh MW, Weitzel JN, Friedlander M, Arun B, Loman N, Schmutzler RK, et al. Oral poly (ADP-ribose) polymerase inhibitor olaparib in patients with BRCA1 or BRCA2 mutations and advanced breast cancer: a proof-of-concept trial. Lancet. 2010;376:9737.

9. Pommier $Y, O^{\prime}$ Connor MJ, de Bono J. Laying a trap to kill cancer cells: PARP inhibitors and their mechanisms of action. Sci Transl Med. 2016;8:362.

10. Chan N, Pires IM, Bencokova Z, Coackley C, Luoto KR, Bhogal N Lakshman M, Gottipati P, Oliver FJ, Helleday T, et al. Contextual synthetic lethality of cancer cell kill based on the tumor microenvironment. Cancer Res. 2010;70:20

11. Dungey FA, Loser DA, Chalmers AJ. Replication-dependent radiosensitization of human glioma cells by inhibition of poly (ADP-ribose) polymerase: mechanisms and therapeutic potential. Int J Radiat Oncol Biol Phys. 2008;72:4.

12. Noel G, Godon C, Fernet M, Giocanti N, Megnin-Chanet F, Favaudon V. Radiosensitization by the poly (ADP-ribose) polymerase inhibitor 4-amino1,8-naphthalimide is specific of the $S$ phase of the cell cycle and involves arrest of DNA synthesis. Mol Cancer Ther. 2006;5:3.

13. Lourenco LM, Jiang Y, Drobnitzky N, Green M, Cahill F, Patel A, Shanneik Y, Moore J, Ryan AJ. PARP inhibition combined with thoracic irradiation exacerbates esophageal and skin toxicity in C57BL6 mice. Int J Radiat Oncol Biol Phys. 2018;100:3

14. Verhagen CV, de Haan R, Hageman F, Oostendorp TP, Carli AL, O'Connor MJ, Jonkers J, Verheij M, van den Brekel MW, Vens C. Extent of radiosensitization by the PARP inhibitor olaparib depends on its dose, the radiation dose and the integrity of the homologous recombination pathway of tumor cells. Radiother Oncol. 2015;116:3.

15. Wurster S, Hennes F, Parplys AC, Seelbach J, Mansour WY, Zielinski A, Petersen C, Clauditz TS, Munscher A, Friedl AA, et al. PARP1 inhibition radiosensitizes HNSCC cells deficient in homologous recombination by disabling the DNA replication fork elongation response. Oncotarget. 2016;7:9.

16. Ali M, Telfer BA, McCrudden C, O'Rourke M, Thomas HD, Kamjoo M, Kyle S, Robson T, Shaw C, Hirst DG, et al. Vasoactivity of AG014699, a clinically active small molecule inhibitor of poly (ADP-ribose) polymerase: a contributory factor to chemopotentiation in vivo? Clin Cancer Res. 2009;15:19.

17. Borst GR, Kumareswaran R, Yucel H, Telli S, Do T, McKee T, Zafarana G, Jonkers J, Verheij M, O'Connor MJ, et al. Neoadjuvant olaparib targets hypoxia to improve radioresponse in a homologous recombinationproficient breast cancer model. Oncotarget. 2017;8:50.

18. Calabrese CR, Almassy R, Barton S, Batey MA, Calvert AH, Canan-Koch S, Durkacz BW, Hostomsky Z, Kumpf RA, Kyle S, et al. Anticancer chemosensitization and radiosensitization by the novel poly (ADP-ribose) polymerase-1 inhibitor AG14361. JNatlCancer Inst. 2004;96:1.

19. Liu SK, Coackley C, Krause M, Jalali F, Chan N, Bristow RG. A novel poly (ADP-ribose) polymerase inhibitor, ABT-888, radiosensitizes malignant human cell lines under hypoxia. RadiotherOncol. 2008;88:2.

20. Senra JM, Telfer BA, Cherry KE, McCrudden CM, Hirst DG, O'Connor MJ, Wedge SR, Stratford IJ. Inhibition of PARP-1 by olaparib (AZD2281) increases the radiosensitivity of a lung tumor xenograft. Mol Cancer Ther. 2011;10:10.

21. Reiss KA, Herman JM, Armstrong D, Zahurak M, Fyles A, Brade A, Milosevic M, Dawson LA, Scardina A, Fischer $P$, et al. A final report of a phase I study of veliparib (ABT-888) in combination with low-dose fractionated whole abdominal radiation therapy (LDFWAR) in patients with advanced solid malignancies and peritoneal carcinomatosis with a dose escalation in ovarian and fallopian tube cancers. Gynecol Oncol. 2017;144:3.

22. Reiss KA, Herman JM, Zahurak M, Brade A, Dawson LA, Scardina A, Joffe C, Petito E, Hacker-Prietz A, Kinders RJ, et al. A phase I study of Veliparib (ABT888 ) in combination with low-dose fractionated whole abdominal radiation therapy in patients with advanced solid malignancies and peritoneal Carcinomatosis. Clin Cancer Res. 2015;21:1.

23. Baxter P, Su J, Li X, Thomas AO, Billups C, Thompson P, Poussaint T, McKeegan E, Wan X, Ansell P et al: EPT-15A Phase 1/2 clinical trial of valiparib (ABT-888) and radiation followed by maintenance therapy with veliparib and temozolomide (TMZ) in patients with newly diagnosed diffuse intrinsic pontine glioma (DIPG): a pediatric brain tumor consortium interim report of phase II study. Neuro-oncol 2016;18:suppl_3.

24. Chabot P, Hsia TC, Ryu JS, Gorbunova V, Belda-Iniesta C, Ball D, Kio E, Mehta M, Papp K, Qin Q, et al. Veliparib in combination with whole-brain radiation therapy for patients with brain metastases from non-small cell lung cancer: results of a randomized, global, placebo-controlled study. J Neuro-Oncol. 2017;131:1.

25. Kleinberg L, Supko JG, Mikkelsen T, O'Neill Blakeley J, Stevens G, Ye X, Desideri S, Ryu S, Desai B, Giranda VL et al: Phase I adult brain tumor consortium (ABTC) trial of ABT-888 (veliparib), temozolomide (TMZ), and radiotherapy (RT) for newly diagnosed glioblastoma multiforme (GBM) including pharmacokinetic (PK) data. J Clin Oncol 2013;31:15_suppl.

26. Litton JK, Rugo HS, Ettl J, Hurvitz SA, Goncalves A, Lee KH, Fehrenbacher L, Yerushalmi R, Mina LA, Martin M, et al. Talazoparib in patients with advanced breast Cancer and a germline BRCA mutation. N Engl J Med. 2018;379:8.

27. Mehta MP, Wang D, Wang F, Kleinberg L, Brade A, Robins HI, Turaka A, Leahy $T$, Medina $\mathrm{D}$, Xiong $\mathrm{H}$, et al. Veliparib in combination with whole brain radiation therapy in patients with brain metastases: results of a phase 1 study. J Neuro-Oncol. 2015.

28. Czito BG, Deming DA, Jameson GS, Mulcahy MF, Vaghefi H, Dudley MW, Holen KD, DeLuca A, Mittapalli RK, Munasinghe W, et al. Safety and tolerability of veliparib combined with capecitabine plus radiotherapy in patients with locally advanced rectal cancer: a phase $1 \mathrm{~b}$ study. Lancet Gastroenterol Hepatol. 2017;2:6.

29. Jagsi R, Griffith KA, Bellon JR, Woodward WA, Horton JK, Ho A, Feng FY, Speers C, Overmoyer B, Sabel M, et al. Concurrent Veliparib with Chest Wall and nodal radiotherapy in patients with inflammatory or Locoregionally recurrent breast Cancer: the TBCRC 024 phase I multicenter study. J Clin Oncol. 2018:36:13.

30. Karam SD, Reddy K, Blatchford PJ, Waxweiler T, DeLouize AM, Oweida A, Somerset $H$, Marshall C, Young C, Davies KD, et al. Final report of a phase I trial of Olaparib with Cetuximab and radiation for heavy smoker patients with locally advanced head and neck Cancer. Clin Cancer Res. 2018.

31. Fulton B, Short SC, James A, Nowicki S, McBain C, Jefferies S, Kelly C, Stobo J, Morris A, Williamson A, et al. PARADIGM-2: two parallel phase I studies of olaparib and radiotherapy or olaparib and radiotherapy plus temozolomide in patients with newly diagnosed glioblastoma, with treatment stratified by MGMT status. Clin Transl Radiat Oncol. 2018;8.

32. Lesueur P, Lequesne J, Grellard JM, Dugue A, Coquan E, Brachet PE, Geffrelot J, Kao W, Emery E, Berro DH, et al. Phase I/Ila study of concomitant radiotherapy with olaparib and temozolomide in unresectable or partially resectable glioblastoma: OLA-TMZ-RTE-01 trial protocol. BMC Cancer. 2019;19:1. 
33. Auperin A, Le Pechoux C, Rolland E, Curran WJ, Furuse K, Fournel P, Belderbos J, Clamon G, Ulutin HC, Paulus R, et al. Meta-analysis of concomitant versus sequential radiochemotherapy in locally advanced nonsmall-cell lung cancer. J Clin Oncol. 2010;28:13.

34. Bradley JD, Paulus R, Komaki R, Masters G, Blumenschein G, Schild S, Bogart J, Hu C, Forster K, Magliocco A, et al. Standard-dose versus high-dose conformal radiotherapy with concurrent and consolidation carboplatin plus paclitaxel with or without cetuximab for patients with stage IIIA or IIIB nonsmall-cell lung cancer (RTOG 0617): a randomised, two-by-two factorial phase 3 study. Lancet Oncol. 2015;16:2.

35. van Diessen JN, Chen C, van den Heuvel MM, Belderbos JS, Sonke JJ. Differential analysis of local and regional failure in locally advanced nonsmall cell lung cancer patients treated with concurrent chemoradiotherapy. Radiother Oncol. 2016;118:3.

36. Brito RA, Valero V, Buzdar AU, Booser DJ, Ames F, Strom E, Ross M, Theriault RL, Frye D, Kau SW et al: Long-term results of combined-modality therapy for locally advanced breast cancer with ipsilateral supraclavicular metastases: The University of Texas M.D. Anderson Cancer Center experience. J Clin Oncol 2001;19:3.

37. Huang EH, Tucker SL, Strom EA, McNeese MD, Kuerer HM, Hortobagyi GN, Buzdar AU, Valero V, Perkins GH, Schechter NR, et al. Predictors of locoregional recurrence in patients with locally advanced breast cancer treated with neoadjuvant chemotherapy, mastectomy, and radiotherapy. Int J Radiat Oncol Biol Phys. 2005;62:2.

38. Harris EE, Schultz D, Bertsch H, Fox K, Glick J, Solin LJ. Ten-year outcome after combined modality therapy for inflammatory breast cancer. Int J Radiat Oncol Biol Phys. 2003;55:5.

39. Li J, Gonzalez-Angulo AM, Allen PK, Yu TK, Woodward WA, Ueno NT, Lucci A, Krishnamurthy S, Gong Y, Bondy ML, et al. Triple-negative subtype predicts poor overall survival and high locoregional relapse in inflammatory breast cancer. Oncologist. 2011;16:12.

40. Ang KK, Zhang Q, Rosenthal DI, Nguyen-Tan PF, Sherman EJ, Weber RS, Galvin JM, Bonner JA, Harris J, El-Naggar AK, et al. Randomized phase III trial of concurrent accelerated radiation plus cisplatin with or without cetuximab for stage III to IV head and neck carcinoma: RTOG 0522. J Clin Oncol. 2014 32:27.

41. Al-Mamgani A, de Ridder M, Navran A, Klop WM, de Boer JP, Tesselaar ME. The impact of cumulative dose of cisplatin on outcome of patients with head and neck squamous cell carcinoma. Eur Arch Otorhinolaryngol. 2017;274:10.

42. Bonner JA, Harari PM, Giralt J, Azarnia N, Shin DM, Cohen RB, Jones CU, Sur $R$, Raben D, Jassem J, et al. Radiotherapy plus cetuximab for squamous-cell carcinoma of the head and neck. N Engl J Med. 2006;354:6.

43. Pignon JP, le Maitre A, Maillard E, Bourhis J, Group M-NC. Meta-analysis of chemotherapy in head and neck cancer (MACH-NC): an update on 93 randomised trials and 17,346 patients. Radiother Oncol. 2009:92:1.

44. Campbell JD, Alexandrov A, Kim J, Wala J, Berger AH, Pedamallu CS, Shukla SA, Guo G, Brooks AN, Murray BA, et al. Distinct patterns of somatic genome alterations in lung adenocarcinomas and squamous cell carcinomas. Nat Genet. 2016;48:6.

45. Chae YK, Anker JF, Carneiro BA, Chandra S, Kaplan J, Kalyan A, Santa-Maria CA, Platanias LC, Giles FJ. Genomic landscape of DNA repair genes in cancer. Oncotarget. 2016;7:17.

46. Coleman RL, Oza AM, Lorusso D, Aghajanian C, Oaknin A, Dean A, Colombo N, Weberpals Jl, Clamp A, Scambia G, et al. Rucaparib maintenance treatment for recurrent ovarian carcinoma after response to platinum therapy (ARIEL3): a randomised, double-blind, placebo-controlled, phase 3 trial. Lancet. 2017;390:10106.

47. Ledermann J, Harter P, Gourley C, Friedlander M, Vergote I, Rustin G, Scott CL, Meier W, Shapira-Frommer R, Safra T, et al. Olaparib maintenance therapy in patients with platinum-sensitive relapsed serous ovarian cancer: a preplanned retrospective analysis of outcomes by BRCA status in a randomised phase 2 trial. Lancet Oncol. 2014;15:8.

48. Mateo J, Carreira S, Sandhu S, Miranda S, Mossop H, Perez-Lopez R, Nava Rodrigues D, Robinson D, Omlin A, Tunariu N, et al. DNA-repair defects and Olaparib in metastatic prostate Cancer. N Engl J Med. 2015;373:18.

49. Swisher EM, Lin KK, Oza AM, Scott CL, Giordano H, Sun J, Konecny GE, Coleman RL, Tinker AV, O'Malley DM et al: Rucaparib in relapsed, platinumsensitive high-grade ovarian carcinoma (ARIEL2 Part 1): an international, multicentre, open-label, phase 2 trial. Lancet Oncol 2017;18:1.

50. Knijnenburg TA, Wang L, Zimmermann MT, Chambwe N, Gao GF, Cherniack $A D$, Fan $H$, Shen $H$, Way GP, Greene CS, et al. Genomic and molecular landscape of DNA damage repair deficiency across the Cancer genome atlas. Cell Rep. 2018;23:1.

51. McCabe N, Turner NC, Lord CJ, Kluzek K, Bialkowska A, Swift S, Giavara S, O'Connor MJ, Tutt AN, Zdzienicka MZ, et al. Deficiency in the repair of DNA damage by homologous recombination and sensitivity to poly (ADP-ribose) polymerase inhibition. Cancer Res. 2006;66:16.

52. Murai J, Huang SY, Das BB, Renaud A, Zhang Y, Doroshow JH, Ji J, Takeda S, Pommier Y. Trapping of PARP1 and PARP2 by clinical PARP inhibitors. Cancer Res. 2012;72:21.

53. Malone KE, Daling JR, Doody DR, Hsu L, Bernstein L, Coates RJ, Marchbanks PA, Simon MS, McDonald JA, Norman SA, et al. Prevalence and predictors of BRCA1 and BRCA2 mutations in a population-based study of breast cancer in white and black American women ages 35 to 64 years. Cancer Res. 2006; $66: 16$

54. Litton J, Rugo HS, Ettl J, Hurvitz S, Gonçalves A, Lee KH, Fehrenbacher L, Yerushalmi R, Mina LA, Martin M et al: Abstract GS6-07: EMBRACA: A phase 3 trial comparing talazoparib, an oral PARP inhibitor, to physician's choice of therapy in patients with advanced breast cancer and a germline < em>BRCA</em> mutation. Cancer Res 2018;78:4 Supplement.

55. Robson M, Im SA, Senkus E, Xu B, Domchek SM, Masuda N, Delaloge S, Li W, Tung N, Armstrong A, et al. Olaparib for metastatic breast Cancer in patients with a germline BRCA mutation. N Engl J Med. 2017;377:6.

56. Verhagen CVM, Vossen DM, Borgmann K, Hageman F, Grenman R, VerwijsJanssen M, Mout L, Kluin RJC, Nieuwland M, Severson TM, et al. Fanconi anemia and homologous recombination gene variants are associated with functional DNA repair defects in vitro and poor outcome in patients with advanced head and neck squamous cell carcinoma. Oncotarget. 2018;9:26

57. Vossen DM, Verhagen CVM, Verheij M, Wessels LFA, Vens C, van den Brekel MWM. Comparative genomic analysis of oral versus laryngeal and pharyngeal cancer. Oral Oncol. 2018;81.

58. Overgaard J. Hypoxic modification of radiotherapy in squamous cell carcinoma of the head and neck--a systematic review and meta-analysis. Radiother Oncol. 2011;100:1.

59. Kwint M, Walraven I, Burgers S, Hartemink K, Klomp H, Knegjens J, Verheij M, Belderbos J. Outcome of radical local treatment of non-small cell lung cancer patients with synchronous oligometastases. Lung Cancer. 2017;112.

60. Ang KK, Harris J, Wheeler R, Weber R, Rosenthal DI, Nguyen-Tan PF, Westra WH, Chung $\mathrm{CH}$, Jordan RC, Lu C, et al. Human papillomavirus and survival of patients with oropharyngeal cancer. N Engl J Med. 2010;363:1.

61. Overgaard J, Hansen HS, Specht L, Overgaard M, Grau C, Andersen E, Bentzen J, Bastholt L, Hansen O, Johansen J, et al. Five compared with six fractions per week of conventional radiotherapy of squamous-cell carcinoma of head and neck: DAHANCA 6 and 7 randomised controlled trial. Lancet. 2003;362:9388

62. Mateo J, Moreno V, Gupta A, Kaye SB, Dean E, Middleton MR, Friedlander M, Gourley C, Plummer R, Rustin G, et al. An adaptive study to determine the optimal dose of the tablet formulation of the PARP inhibitor Olaparib. Target Oncol. 2016;11:3.

63. Ivy SP, Siu LL, Garrett-Mayer E, Rubinstein L. Approaches to phase 1 clinical trial design focused on safety, efficiency, and selected patient populations: a report from the clinical trial design task force of the national cancer institute investigational drug steering committee. Clin Cancer Res. 2010;16:6.

64. Cheung YK, Chappell R. Sequential designs for phase I clinical trials with late-onset toxicities. Biometrics. 2000;56:4.

65. Normolle D, Lawrence T. Designing dose-escalation trials with late-onset toxicities using the time-to-event continual reassessment method. J Clin Oncol. 2006;24:27

66. Harrington KJ, Billingham $L$, Brunner TB, Burnet NG, Chan CS, Hoskin P, Mackay RI, Maughan TS, Macdougall J, McKenna WG, et al. Guidelines for preclinical and early phase clinical assessment of novel radiosensitisers. $\mathrm{Br}$ J Cancer. 2011;105:5.

67. Pijls-Johannesma M, van Mastrigt G, Hahn SM, De Ruysscher D, Baumert BG, Lammering G, Buijsen J, Bentzen SM, Lievens Y, Kramar A, et al. A systematic methodology review of phase I radiation dose escalation trials. Radiother Oncol. 2010;95:2.

68. Sharma RA, Plummer R, Stock JK, Greenhalgh TA, Ataman O, Kelly S, Clay R, Adams RA, Baird RD, Billingham $L$, et al. Clinical development of new drugradiotherapy combinations. Nat Rev Clin Oncol. 2016;13:10.

69. Rose MA, Olivotto I, Cady B, Koufman C, Osteen R, Silver B, Recht A, Harris $J R$. Conservative surgery and radiation therapy for early breast cancer. Longterm cosmetic results Arch Surg. 1989;124:2 
70. Bundred N, Gardovskis J, Jaskiewicz J, Eglitis J, Paramonov V, McCormack P, Swaisland $\mathrm{H}$, Cavallin M, Parry T, Carmichael J, et al. Evaluation of the pharmacodynamics and pharmacokinetics of the PARP inhibitor olaparib: a phase I multicentre trial in patients scheduled for elective breast cancer surgery. Investig New Drugs. 2013.

71. Nijenhuis CM, Lucas L, Rosing H, Schellens JH, Beijnen JH. Development and validation of a high-performance liquid chromatography-tandem mass spectrometry assay quantifying olaparib in human plasma. J Chromatogr B Analyt Technol Biomed Life Sci. 2013;940.

72. de Haan R, Pluim D, van Triest B, van den Heuvel M, Peulen H, van Berlo D, George J, Verheij M, Schellens JHM, Vens C. Improved pharmacodynamic (PD) assessment of low dose PARP inhibitor PD activity for radiotherapy and chemotherapy combination trials. Radiother Oncol. 2018;126:3.

73. Bentzen SM. Preventing or reducing late side effects of radiation therapy: radiobiology meets molecular pathology. Nat Rev Cancer. 2006;6:9.

74. De Jaeger K, Seppenwoolde Y, Kampinga HH, Boersma LJ, Belderbos JS, Lebesque JV. Significance of plasma transforming growth factor-beta levels in radiotherapy for non-small-cell lung cancer. Int J Radiat Oncol Biol Phys. 2004;58:5.

75. Jiang Y, Verbiest T, Devery AM, Bokobza SM, Weber AM, Leszczynska KB, Hammond EM, Ryan AJ. Hypoxia potentiates the radiation-sensitizing effect of Olaparib in human non-small cell lung Cancer xenografts by contextual synthetic lethality. Int J Radiat Oncol Biol Phys. 2016;95:2.

76. Cheung K: R software version 3.5.0 package dfcrm version 0.2-2. https:// CRAN.R-project.org/package=dfcrm. 2013.

77. Ree AH, Hollywood D. Design and conduct of early-phase radiotherapy trials with targeted therapeutics: lessons from the PRAVO experience. Radiother Oncol. 2013;108:1.

78. Donawho CK, Luo Y, Luo Y, Penning TD, Bauch JL, Bouska JJ, BontchevaDiaz VD, Cox BF, DeWeese TL, Dillehay LE, et al. ABT-888, an orally active poly (ADP-ribose) polymerase inhibitor that potentiates DNA-damaging agents in preclinical tumor models. ClinCancer Res. 2007;13:9.

79. Rottenberg S, Jaspers JE, Kersbergen A, van der Burg E, Nygren AO, Zander SA, Derksen PW, de Bruin M, Zevenhoven J, Lau A, et al. High sensitivity of BRCA1-deficient mammary tumors to the PARP inhibitor AZD2281 alone and in combination with platinum drugs.

ProcNatlAcadSciU S A. 2008;105:44.

80. Socinski MA, Stinchcombe TE, Moore DT, Gettinger SN, Decker RH, Petty WJ, Blackstock AW, Schwartz G, Lankford S, Khandani A, et al. Incorporating bevacizumab and erlotinib in the combined-modality treatment of stage III non-small-cell lung cancer: results of a phase I/II trial. J Clin Oncol. 2012;30:32.

81. van den Heuvel MM, Uyterlinde W, Vincent AD, de Jong J, Aerts J, Koppe F, Knegjens J, Codrington H, Kunst PW, Dieleman E, et al. Additional weekly Cetuximab to concurrent chemoradiotherapy in locally advanced non-small cell lung carcinoma: efficacy and safety outcomes of a randomized, multicenter phase II study investigating. Radiother Oncol. 2014;110:1.

82. Chemoradiotherapy for Cervical Cancer Meta-analysis C: Reducing uncertainties about the effects of chemoradiotherapy for cervical cancer: individual patient data meta-analysis. Cochrane Database Syst Rev 2010:1.

83. Forastiere AA, Goepfert H, Maor M, Pajak TF, Weber R, Morrison W, Glisson B, Trotti A, Ridge JA, Chao C, et al. Concurrent chemotherapy and radiotherapy for organ preservation in advanced laryngeal cancer. N Engl J Med. 2003;349:22.

84. Balmana J, Tung NM, Isakoff SJ, Grana B, Ryan PD, Saura C, Lowe ES, Frewer $P$, Winer $E$, Baselga J, et al. Phase I trial of olaparib in combination with cisplatin for the treatment of patients with advanced breast, ovarian and other solid tumors. Ann Oncol. 2014;25:8.

85. Uyterlinde W, Belderbos J, Baas C, van Werkhoven E, Knegjens J, Baas P, Smit A, Rikers $C$, van den Heuvel M. Prediction of acute toxicity grade $>/=3$ in patients with locally advanced non-small-cell lung cancer receiving intensity modulated radiotherapy and concurrent low-dose cisplatin. Clin Lung Cancer. 2013;14:5.

86. Begg AC. Cisplatin and radiation: interaction probabilities and therapeutic possibilities. Int J Radiat Oncol Biol Phys. 1990;19:5.

87. Abel S, Renz P, Trombetta M, Cowher M, Day Werts E, Julian TB, Wegner R. Local failure and acute radiodermatological toxicity in patients undergoing radiation therapy with and without postmastectomy chest wall bolus: is bolus ever necessary? Pract Radiat Oncol. 2017;7:3.

88. Damast S, Ho AY, Montgomery L, Fornier MN, Ishill N, Elkin E, Beal K, McCormick B. Locoregional outcomes of inflammatory breast cancer patients treated with standard fractionation radiation and daily skin bolus in the taxane era. Int J Radiat Oncol Biol Phys. 2010;77:4.

89. Tieu MT, Graham P, Browne L, Chin YS. The effect of adjuvant postmastectomy radiotherapy bolus technique on local recurrence. Int J Radiat Oncol Biol Phys. 2011;81:3.

90. Chen C, Uyterlinde W, Sonke JJ, de Bois J, van den Heuvel M, Belderbos J. Severe late esophagus toxicity in NSCLC patients treated with IMRT and concurrent chemotherapy. Radiother Oncol. 2013;108:2.

91. Marks LB, Bentzen SM, Deasy JO, Kong FM, Bradley JD, Vogelius IS, El Naqa I, Hubbs JL, Lebesque JV, Timmerman RD et al: Radiation dose-volume effects in the lung. Int J Radiat Oncol Biol Phys 2010;76:3 Suppl.

\section{Publisher's Note}

Springer Nature remains neutral with regard to jurisdictional claims in published maps and institutional affiliations.

\section{Ready to submit your research? Choose BMC and benefit from:}

- fast, convenient online submission

- thorough peer review by experienced researchers in your field

- rapid publication on acceptance

- support for research data, including large and complex data types

- gold Open Access which fosters wider collaboration and increased citations

- maximum visibility for your research: over $100 \mathrm{M}$ website views per year

At BMC, research is always in progress.

Learn more biomedcentral.com/submissions 